\title{
Prevalence of Insomnia in an Oncology Patient Population: An Irish Tertiary Referral Center Experience
}

Emily C. Harrold, MD; Ahmad F. Idris, $\mathrm{MD}^{2}$; Niamh M. Keegan, MD³; Lynda Corrigan, MD²; Min Yuen Teo, MD; Martin O’Donnell, MD4; Sean Tee Lim, MD4; Eimear Duff, MD4; Dearbhaile M. O’Donnell, MD²; M. John Kennedy, MD²; Sue Sukor, MD²; Cliona Grant, MD²; David G. Gallagher, $\mathrm{MD}^{2}$; Sonya Collier, DClinPsych"; Tara Kingston, MD, MRCPsych, MSc ${ }^{5}$; Ann Marie O’Dwyer, MD5; and Sinead Cuffe, MD²

\section{ABSTRACT}

Background: The NCCN Guidelines for Survivorship recommend dedicated sleep assessment. Reported insomnia prevalence in the general Irish population is $6 \%$ to $15 \%$. Reported insomnia prevalence internationally among new/recently diagnosed patients with cancer varies from $30.9 \%$ to $54.3 \%$. Insomnia prevalence has not been previously quantified in an Irish oncology cohort. Methods: A 40-item questionnaire was prospectively administered to ambulatory patients with cancer aged $\geq 18$ years. Prespecified criteria to define insomnia syndrome combined those of the International Classification of Sleep Disorders, version 1, and the Diagnostic and Statistical Manual of Mental Disorders, Fourth Edition (DSM-IV). The Hospital Anxiety and Depression Scale-Depression/Anxiety (HADS-D/A) was used to screen for potential confounding variables. Results: The response rate to the questionnaire was $87 \%$ (294/337). The predominant respondent age group was 55 to 64 years (26\%; 77/294), $70.7 \%$ were female $(208 / 294)$, and the most common cancer subtypes were breast (37.4\%), colorectal (12.9\%), and lung (12.2\%). A total of $62 \%$ $(183 / 294)$ of patients reported sleep disturbance after diagnosis, 63\% (115/ 183) reported moderate/severe distress related to this disturbance, and $37 \%(61 / 183)$ reported a significant impact on physical function. Although $33 \%$ (98/294) met insomnia syndrome criteria, only $34 \%$ (33/98) of these patients had a preexisting history of sleep disturbance. Female sex, age $<65$ years, cancer subtype, alcohol consumption, and HADS-D/A $\geq 11$ were associated with statistically significant higher odds ratios (OR) of insomnia syndrome. Multivariate analysis identified breast cancer $(\mathrm{OR}$, 3.17; $P=.01)$, age $<65$ years $(\mathrm{OR}, 1.8 ; P=.03)$, and alcohol consumption $(\mathrm{OR}, 2.3 ; P=.005)$ as independent predictors of insomnia syndrome. Conclusions: Insomnia syndrome prevalence in this cohort is comparable to that reported previously and supports dedicated sleep assessment. This study identifies potentially modifiable risk factors for insomnia and demonstrates additional utility of the HADS score in identifying patients at risk.

J Natl Compr Canc Netw 2020;18(12):1623-1630 doi: 10.6004/jnccn.2020.7611

${ }^{1}$ Department of Medical Oncology, Mater Misericordiae University Hospital, Dublin, Ireland; ${ }^{2}$ Department of Medical Oncology, St. James's Hospital, Dublin, Ireland; ' ${ }^{3}$ Department of Medical Oncology, Memorial Sloan Kettering Cancer Center, New York, New York; ${ }^{4}$ Trinity College Medical School, Dublin, Ireland; and ${ }^{5}$ Department of Psychological Oncology Medicine, St. James's University Hospital, Dublin, Ireland.

See JNCCN.org for supplemental online content.

\section{Background}

The WHO estimates that by 2020, 15.5 million people will experience cancer and global cancer deaths will increase from 7.1 million in 2002 to 11.5 million in $2030 .{ }^{1}$ Both insomnia and depression often develop as associated psychologic comorbidities and can become chronic issues even in the event of remission. Insomnia is more common among patients with cancer than among the general population ${ }^{2}$ and those with nonmalignant medical conditions. ${ }^{3,4}$ Insomnia is a significant independent predictor of reduced patient functioning when function 3 months prior to diagnosis is compared with function 8 weeks postdiagnosis, ${ }^{5}$ regardless of cancer site or stage. Quantification of insomnia syndrome is important from a morbidity and quality-of-life perspective, but also because of potential interaction with mortality. ${ }^{6}$ Among the general population, emerging epidemiologic data suggest higher rates of all-cause mortality for individuals with shortened duration of sleep. ${ }^{7-11}$ Insomnia is equally associated with higher mortality rates among cardiology patients ${ }^{12,13}$ and poorer prognosis among patients with chronic diseases. ${ }^{14}$ In addition, increased standardized incidence rates of liver and lung cancer have been noted among patients with newly diagnosed sleep disorders. ${ }^{15}$

Although sleep disturbance is commonly reported among patients with cancer, ${ }^{16}$ data regarding exact prevalence of insomnia syndrome distinct from sleep disturbance are more limited. One of the challenges in interpreting the literature is poor differentiation between symptoms of insomnia and insomnia syndrome. A variety of screening tools have been used across heterogeneous patient groups ${ }^{17}$ (supplemental Appendix 1 and eTable 1; available with this article at JNCCN.org), and often long-term follow-up data are not available.

See page 1738 for related commentary. 
Reported insomnia prevalence among patients newly diagnosed with or recently treated for cancer varies from $30.9 \%$ to $54.3 \% .{ }^{18-22}$ Similarly high rates of insomnia symptoms, $23 \%$ to $44 \%,{ }^{23-27}$ have been identified up to 5 years after initiation of adjuvant therapy for cancer, and insomnia continues to remain a significant issue among long-term survivors ( $>5$ years), ${ }^{28,29}$ illustrating the chronicity of this sleep disturbance. Sleep disturbance has been reported in nearly $50 \%$ of patients with advanced cancer ${ }^{30}$ and is associated with increased pain, depression, anxiety, and a worse sense of wellbeing. ${ }^{31}$ At a practical level, patients may be reluctant to report their symptoms due to the belief that sleep disturbance is a natural consequence of their diagnosis, and medical staff may be reluctant to pose relevant questions due to lack of expertise in managing these symptoms. Despite this, $25 \%$ to $50 \%$ of all psychotropic prescriptions written for patients who have cancer are for hypnotics. ${ }^{32,33}$

To our knowledge, insomnia prevalence has not previously been quantified in an Irish oncology cohort. The NCCN Clinical Practice Guidelines in Oncology (NCCN Guidelines) for Survivorship ${ }^{34}$ recommend dedicated sleep assessment, reflecting acknowledgment of the increased insomnia prevalence among patients with cancer, and its association with increased symptom distress scores. The Irish Sleep Apnoea Trust reports that insomnia affects $6 \%$ to $15 \%$ of the general Irish population; a multinational European study in the general population that included Ireland reported a rate of $7 \%$ of severe insomnia, with higher rates among women than men. ${ }^{35}$

\section{Methods}

We conducted a prospective nonblinded questionnairebased study over a 6-month period from June to December 2014 at a single tertiary-level Irish hospital, in collaboration with the psycho-oncology service to ensure that any significant mental health issues identified through study participation were dealt with in a sensitive and expeditious manner.

Institutional ethical board approval was obtained and a 40-item questionnaire (supplemental eAppendix 1) was prospectively administered to ambulatory patients with cancer attending either the oncology day ward or the outpatient clinic. Inclusion criteria were confirmed cancer diagnosis, age $\geq 18$ years, ability to read and complete a questionnaire, and capacity to provide informed consent. All eligible patients were invited to participate. After providing consent, participants completed a self-report questionnaire encompassing demographic and clinical data, patient-reported functional status, ${ }^{36,37}$ and the Hospital Anxiety and Depression Scale (HADS). ${ }^{38}$ Inpatients were excluded from this study. The primary study endpoint was assessment of the prevalence of insomnia syndrome among the ambulatory patient cohort. Secondary endpoints included investigation of predisposing, precipitating, and perpetuating factors for insomnia syndrome.

\section{Data Reduction}

Our prespecified criteria for insomnia syndrome combines those of the International Classification of Sleep Disorders, version 1,39 and the Diagnostic and Statistical Manual of Mental Disorders (Fourth Edition; DSM-IV) ${ }^{40}$ and were described by Savard and Morin ${ }^{17}$ in their comprehensive review of insomnia among patients with cancer. The 4 criteria used were (1) difficulty initiating sleep or difficulty maintaining sleep, (2) sleep disturbance occurring $\geq 3$ nights per week, (3) sleep disturbance causing significant impairment of daytime functioning or severe distress, and (4) sleep disturbance present $\geq 1$ month. Patients who met all 4 criteria were coded as having insomnia syndrome. Impact on daytime functioning and distress was self-reported and not objectively assessed. Those who met some but not all 4 criteria were coded as having insomnia symptoms.

\section{Assessments}

The 40-item questionnaire (supplemental eAppendix 1) was designed to incorporate the sleep-related components of the Hamilton Depression Rating Scale ${ }^{41}$ quantify duration and nature of sleep disturbance, evaluate sleep hygiene in the context of well-described precipitating and perpetuating factors for sleep disturbance, ${ }^{17}$ and evaluate patients' experiences of inquiries regarding sleep disturbance and preferences for intervention.

The Patient-Reported Functional Status (PRFS) is a patient-completed measure of performance status that represents the activities/function domain of the Patient-Generated Subjective Global Assessment (PG-SGA) measure. ${ }^{37,42}$ It is based on the ECOG scale but is expressed in lay terms. ${ }^{36,43}$ In contrast to the ECOG scale, it is a 5 -point scale in which 0 is "normal with no limitations," 1 is "not my normal self, but able to be up and about with fairly normal activities," 2 is "not feeling up to most things, but in bed or chair less than half the day," 3 is "able to do little activity and spend most of the day in bed or chair," and 4 is "pretty much bedridden, rarely out of bed."

HADS $^{38}$ was used to screen for depression (HADS-D) and anxiety (HADS-A) as potential confounding variables. This measure is frequently used among patients with cancer because it is characterized by an absence of somatic symptoms that may be attributable to either medical or psychiatric conditions. HADS is a 14 -item questionnaire and each item has a Likert response scale. Final scores are cumulative, with higher scores suggestive of a case. The cutoff value used for cases was a score of $\geq 11$, consistent with the original authors' 
description of the scale and with an indication of moderate severity of either anxiety or depression. We are aware that lower values have been suggested in some more recent literature. ${ }^{44}$ We used this scale to assess for anxiety and depression as 2 separate variables, as proposed by its original authors, rather than a combined score, which has been proposed elsewhere. ${ }^{44}$ The validity of separating the 2 subscales in patients with cancer was confirmed in 568 patients by Moorey et $\mathrm{al}^{45}$; use of HADS to detect anxiety and depressive states separately in a 2-factor model has also been found to be invariant across sex or disease phase among patients with cancer. ${ }^{46}$

\section{Data Analysis}

All patients who accepted and at least partially completed the questionnaire were included for the purpose of data analysis. To explore clinical and demographic factors potentially associated with insomnia syndrome, we first performed univariate logistical regression analysis on factors such as sex, age, alcohol consumption, HADS-D and HADS-A scores, cancer subtypes, smoking status, caffeine and corticosteroid use, and surgery. All variables that had a $P$ value of $<.05$ were then entered into a multivariate logistical regression model to identify potential independent predictors of insomnia syndrome.

\section{Results}

\section{Demographic and Clinical Characteristics}

Of the 337 patients invited to participate, $87 \%$ consented to study inclusion ( $\mathrm{n}=294) ; 12$ declined without explanation, 15 were too unwell to participate, 8 declined due to lack of appropriate reading aids, 4 declined due to language difficulties, and 4 declined due to time constraints.

Table 1 lists the baseline demographics, cancer subtype, and treatment modalities received by our patient cohort. The predominant respondent age group was 55 to 64 years $(n=77 ; 26 \%)$, and $70.7 \%(n=208)$ of respondents were female. Consistent with an ambulatory patient cohort, $81.3 \%(n=239)$ of patients had a self-reported performance status ${ }^{36}$ of 0 to 1 . Breast, colorectal, and lung were the most common cancer subtypes represented. Most respondents $(n=245 ; 83.3 \%$ ) were receiving active chemotherapy, slightly more than one-half $(56.6 \%)$ had undergone oncologic surgery, and $17 \%(n=50)$ had been hospitalized in the month prior to completion of our questionnaire.

\section{Insomnia Syndrome}

A total of $62 \%(n=183)$ of patients reported sleep disturbance after their diagnosis; of these, $37 \%(n=67)$ reported a significant impact on physical function and $63 \%(\mathrm{n}=115)$ reported moderate to severe distress relating to this disturbance. Concerningly, 19\% $(n=34)$ indicated that their sleep disturbance had impacted their ability to tolerate further treatment and $24 \%(n=44)$ felt it had impacted their cognition.

Among the entire cohort, 33\% $(n=98)$ of patients met all 4 prespecified criteria for insomnia syndrome (ie, they reported difficulty initiating sleep or difficulty maintaining sleep, sleep disturbance occurring $\geq 3$ nights per week, sleep disturbance causing significant impairment of daytime functioning or severe distress, and sleep disturbance present $\geq 1$ month). Only $34 \%(n=33)$ of patients who met insomnia syndrome criteria had any preexisting history of sleep disturbance. Of the patients who did not meet insomnia syndrome criteria, $45 \%(\mathrm{n}=89)$ had $\geq 1$ of the 4 critical diagnostic symptoms: 69 had 1 symptom, 19 had 2 symptoms, and 1 patient had 3 symptoms.

Among the entire cohort, 6\% $(n=18)$ of patients had a HADS score of $\geq 11$, with 10 of these patients having both HADS-D and HADS-A $\geq 11$. The patients with a HADS score of $\geq 11$ were contacted individually regarding potential referral to psycho-oncology based on patient preference, in addition to further clinical assessment; 3 were already attending psycho-oncology, 3 requested referral, and 12 patients declined referral. Patients' treating physicians were informed of high HADS-D/A scores so that these patients' psychologic status could be more closely monitored with additional opportunities for referral if required.

By univariate analysis, female sex, age $<65$ years, cancer subtype, alcohol consumption, and HADS-D/A score $\geq 11$ were associated with statistically significant higher odds ratios of insomnia syndrome (Table 2). Multivariate analysis demonstrated 3 independent predictors of insomnia syndrome: breast cancer (odds ratio [OR], 3.17; $P=.01$ ), age $<65$ years (OR, $1.8 ; P=.03)$, and alcohol consumption (OR, 2.3; $P=.005)$ (Table 3$)$.

\section{Sleep Hygiene}

Alcohol consumption, low level of physical activity, high caffeine intake, and electronic stimulus prior to going to bed are all recognized as factors that impact sleep negatively. ${ }^{47}$

At the time of study, $67.4 \%(\mathrm{n}=198)$ of patients reported alcohol consumption; 36 patients did not complete further questions regarding regularity of alcohol consumption. Of those who did respond to more detailed questions regarding alcohol consumption, $76 \%(\mathrm{n}=196)$ reported alcohol consumption no more than once per week and $24 \%(n=62)$ more than once per week. Overall, $12 \%(n=34)$ of all respondents had used alcohol on occasion as a sleep aid and $45 \%(n=132)$ of patients were 


\begin{tabular}{|c|c|}
\hline Characteristic & n (\%) \\
\hline \multicolumn{2}{|l|}{ Sex } \\
\hline Male & $86(29.3)$ \\
\hline Female & $208(70.7)$ \\
\hline \multicolumn{2}{|l|}{ Age, y } \\
\hline$<65$ & $183(62.2)$ \\
\hline$\geq 65$ & $111(37.8)$ \\
\hline \multicolumn{2}{|l|}{ Ethnicity } \\
\hline White/Caucasian & $284(96.6)$ \\
\hline Black/African American & $3(1.0)$ \\
\hline Asian/Other & $7(2.4)$ \\
\hline \multicolumn{2}{|l|}{ Children at home } \\
\hline Yes & $121(41.2)$ \\
\hline No & $172(58.5)$ \\
\hline Unanswered & $1(0.3)$ \\
\hline \multicolumn{2}{|l|}{ Currently working } \\
\hline Yes & $64(21.8)$ \\
\hline No & $230(78.2)$ \\
\hline \multicolumn{2}{|l|}{ Smoking status } \\
\hline Current & $28(9.5)$ \\
\hline Former & $141(48.0)$ \\
\hline Never & $125(42.5)$ \\
\hline \multicolumn{2}{|l|}{ Alcohol consumption } \\
\hline Yes & $198(67.4)$ \\
\hline No & $95(32.3)$ \\
\hline Unanswered & $1(0.2)$ \\
\hline \multicolumn{2}{|l|}{ Performance status } \\
\hline $0-1$ & 239 (81.3) \\
\hline $2-3$ & $55(18.7)$ \\
\hline
\end{tabular}

unaware that alcohol consumption could impact sleep. Notably, among the 98 patients with insomnia syndrome, $80 \%(n=79)$ reported alcohol consumption at the time of study participation.

A total of $81.3 \%(n=239)$ of the entire study population self-reported a performance status of 0 to 1 , and consequently it is unsurprising that more than one-half $(54 \% ; n=159)$ of the patients reported physical activity lasting at least 30 minutes more than once per week. A minority of patients in the entire study population engaged in meditation $(7 \% ; n=22)$, yoga $(6 \% ; n=19)$, mindfulness $(5 \% ; n=14)$, Pilates $(2 \% ; n=5)$, and acupuncture $(1 \% ; \mathrm{n}=3)$.

Of the 98 patients with insomnia syndrome, $98 \%$ $(n=79)$ drank caffeine in some form every day, and significantly more than one-half reported drinking

\begin{tabular}{|c|c|}
\hline Characteristic & n (\%) \\
\hline \multicolumn{2}{|l|}{ Cancer subtype } \\
\hline Breast & $110(37.4)$ \\
\hline Colorectal & $38(12.9)$ \\
\hline Lung & $36(12.2)$ \\
\hline Gynecologic & $33(11.2)$ \\
\hline Gastric/Hepatobiliary & $10(3.4)$ \\
\hline Esophageal & $11(3.7)$ \\
\hline Genitourinary & $6(2.0)$ \\
\hline Head and neck & $14(4.8)$ \\
\hline Other & $18(6.1)$ \\
\hline \multicolumn{2}{|l|}{ Chemotherapy } \\
\hline Currently receiving & $245(83.3)$ \\
\hline Previously received & $33(11.3)$ \\
\hline Planned & $13(4.4)$ \\
\hline Never/Not planned & $3(1.0)$ \\
\hline \multicolumn{2}{|l|}{ Radiotherapy } \\
\hline Currently receiving & $9(3.0)$ \\
\hline Previously received & $112(38.0)$ \\
\hline Planned & $156(53.1)$ \\
\hline Never/Not planned & $93(31.6)$ \\
\hline \multicolumn{2}{|l|}{ Surgery } \\
\hline Yes & $166(56.5)$ \\
\hline No & $127(43.2)$ \\
\hline Unanswered & $1(0.3)$ \\
\hline \multicolumn{2}{|c|}{ Hospitalization in the last month } \\
\hline Yes & $50(17.0)$ \\
\hline No & $242(82.3)$ \\
\hline Unanswered & $2(0.7)$ \\
\hline
\end{tabular}

caffeine-containing beverages after 6:00 PM; $9.8 \%(n=10)$ reported drinking caffeine after 10:00 PM.

In terms of electronic stimuli, in the hour before bed, $85 \%(n=84)$ of patients with insomnia syndrome watched television and $89 \%(n=87)$ reported either television or computer use.

\section{Previous Inquiry and Preferences for Intervention}

Among all respondents, $62 \%(n=182)$ thought that cancer management should incorporate sleep assessment, but only $34 \%(n=100)$ recalled having such an assessment. Of the patients who recalled previous inquiries about sleep disturbance, $27 \%$ had been asked by their oncologist, which was comparable to the $27 \%$ who reported similar inquiries from their general practitioner. Other patients reported being questioned by the oncology nurse (18\%), palliative care team (15\%), and palliative care nurses (5\%). 


\section{Table 2. Univariate Analysis}

\begin{tabular}{|c|c|c|c|}
\hline & Patients, N & Odds Ratio $(95 \% \mathrm{Cl})$ & $P$ Value \\
\hline Age $<65$ y & 183 & $2.5(1.5-4.4)$ & .001 \\
\hline HADS-D $\geq 11$ & 18 & $3.6(1.3-10.8)$ & .011 \\
\hline HADS-A $\geq 11$ & 32 & $2.6(1.3-5.5)$ & .009 \\
\hline Caffeine & 270 & $1.2(0.5-3.4)$ & .615 \\
\hline Steroids & 193 & $1.1(0.6-1.9)$ & .887 \\
\hline Smoker vs nonsmoker & 28 vs 125 & $1.8(0.7-4.4)$ & .184 \\
\hline Smoker vs ex-smoker & 28 vs 141 & $1.3(0.5-3.0)$ & .600 \\
\hline Surgery & 166 & $1.6(1.0-2.7)$ & .055 \\
\hline Previous radiotherapy vs current & 112 vs 9 & $1.75(0.4-12.1)$ & .480 \\
\hline Never treated with radiotherapy vs current & 156 vs 9 & $2.2(0.5-15.3)$ & .297 \\
\hline Previous history of anxiety & 68 & $1.8(1.0-3.1)$ & .044 \\
\hline Previous history of depression & 40 & $1.9(1.0-3.8)$ & .066 \\
\hline
\end{tabular}

Abbreviations: HADS-A, Hospital Anxiety and Depression Scale-Anxiety; HADS-D, Hospital Anxiety and Depression Scale-Depression.

Regarding preferred intervention, respondents were asked to indicate on a Likert scale their degree of comfort with a variety of interventions; a score of 10 indicated that patients would be extremely comfortable with the relevant intervention, whereas a score of 1 implied indifference. Written information (mean score, 5.96; 95\% CI, 5.52-6.41), mindfulness therapy (mean score, 4.87; 95\% CI, 4.43-5.32), and a once-off lecture on sleep management (mean score, 4.82; 95\%, CI, 4.38-5.26) were favored over pharmacologic intervention (ie, sleeping tablets) (mean score, 4.58; $95 \%$ CI, 4.16-5.00). Respondents allocated a mean score of $3.92(95 \%$ CI, 3.52-4.32) to an individual session with a psychiatrist/psychologist and a mean score of $4.12(95 \%$ CI, 3.71-4.52) to cognitive behavioral therapy (CBT). A series of lectures or group workshops on sleep management were the least popular, with mean scores of 3.57 (95\% CI, 3.20-3.95) and 3.54 (95\% CI, 3.16-3.92), respectively. This pattern of patient preference is further corroborated by evaluating the frequency distribution of the scores allocated to each of the interventions (supplemental eTable 2).

\section{Discussion}

Insomnia is a significant problem for patients with cancer at all stages of their treatment trajectory, with an impact on multiple functional domains and a deleterious effect on overall quality of life. ${ }^{48}$ Improving sleep outcomes is significantly related to improvements in quality of life and reduced daytime fatigue. ${ }^{49}$ Data also suggest an association between rest/activity cycles and both response to treatment and overall survival. ${ }^{6}$

Insomnia incidence in this Irish cohort of patients with cancer was more than twice that of the general population. It was comparable to findings reported elsewhere and would justify dedicated sleep assessment. ${ }^{2-4}$ One-third of our patient cohort met criteria for insomnia syndrome and most had no preexisting history of sleep disorder, suggesting causality with both their diagnosis and treatment. Similar to the findings of Palesh et $\mathrm{al}^{50}$ among 826 patients attending oncology private practice groups in the United States, younger age and female sex represent significant risk factors for insomnia syndrome in our Irish cohort. Both these factors and cancer subtype are obviously nonmodifiable but should lower the threshold of clinical vigilance to screen for significant sleep disorders. Two-thirds of patients in our study drank alcohol no more than once per week;

\begin{tabular}{|lcc|}
\hline Table 3. Multivariate Analysis & \\
\hline $\begin{array}{c}\text { Odds Ratio } \\
\text { (95\% Cl) }\end{array}$ & P Value \\
\hline Breast cancer & $3.17(1.2-9.0)$ & .01 \\
\hline Alcohol consumption & $2.3(1.3-4.4)$ & .005 \\
\hline Age $<65$ y & $1.8(1.1-3.4)$ & .03 \\
\hline
\end{tabular}


concerningly, $>10 \%$ of these patients had occasionally used alcohol as a sleep aid and nearly half were unaware it could impact sleep patterns detrimentally. Alcohol consumption is a modifiable risk factor that independently predicts insomnia syndrome in our patient cohort.

Insomnia is often described as existing within a symptom cluster with close association to anxiety, depression, and fatigue. ${ }^{51-54}$ Preexisting psychologic morbidity is also a consideration, particularly among patients with breast cancer. ${ }^{55,56}$ In our cohort, HAD score of $\geq 11$ increased the OR of insomnia syndrome, demonstrating additional utility of this scale. It also allowed us to identify and expeditiously refer these patients to our psycho-oncology colleagues.

One limitation of our study was that although our questionnaire integrated components of previously validated scales, the questionnaire itself has not been externally validated. Equally, our study used a point prevalence self-reported questionnaire without objective measures of sleep disturbance and insomnia. Polysomnography is considered the gold standard for measurement, but it is cumbersome for patients who have cancer, and consequently is used in few studies. ${ }^{54,57}$ Our study also relied on self-report of impact of sleep disturbance on both physical and cognitive function.

Pharmacologic intervention in the form of hypnotics is the most commonly prescribed intervention for insomnia ${ }^{58}$ yet more specific data in terms of efficacy among patients with cancer is required ${ }^{59}$ In our cohort, patient preference was for nonpharmacologic interventions ranging from written information, to mindfulness therapy, to once-off lectures and CBT. In noncancer groups, CBT for insomnia (CBT-I) consisting of 4 key components-sleep restriction, stimulus control, cognitive restructuring, and relaxation training - is the most effective and durable treatment for insomnia. It has also been validated among patients with cancer in several randomized trials. ${ }^{49,60-63}$

In the current setting of restricted resources, alternative strategies to individual CBT-I need to be evaluated. Group therapy as compared with individual CBT has been shown to be effective in patients without cancer both as an early intervention and for chronic insomnia. ${ }^{64,65}$ Equally, computer-based interventions, ${ }^{66}$ telephone-based consultations, ${ }^{67}$ and self-help strategies $^{68}$ have all demonstrated efficacy in noncancer populations. Data in patients with cancer are more limited but remain encouraging and potentially more immediately applicable. Ritterband et al ${ }^{69}$ investigated the feasibility of an internet-based CBT tool, and reported that the intervention group had greater improvements in insomnia severity, sleep efficiency, sleep onset latency, and sleep quality compared with the control group. Savard et $\mathrm{al}^{70}$ demonstrated the feasibility of a self-help program for treating insomnia comorbid with cancer, with statistically and clinically meaningful improvements in numerous sleep variables and overall quality of life. The investigators subsequently conducted a 3-arm randomized controlled trial comparing video-based CBT versus professionally delivered CBT versus no treatment in 242 patients with breast cancer. ${ }^{71}$ Although face-to-face delivery was associated with superior remission rates and improvements in overall insomnia severity, both CBT groups reported clinically meaningful improvements in sleep variables compared with the control group. Less resource-intensive models of CBT-I delivery represent an important option, particularly in centers without dedicated psycho-oncology services, and require further exploration.

Sleep hygiene is considered ineffective as monotherapy, but does promote behaviors that facilitate sleep in an attempt to limit those that contribute to insomnia. ${ }^{61}$ In the trial by Dirksen and Epstein, ${ }^{61}$ the control group received sleep education and information on sleep hygiene. Even addressing sleep disturbances at this low level of complexity seemed to produce meaningful improvements in sleep patterns. Our cohort demonstrated lack of awareness regarding sleep hygiene and exhibited behaviors that have the potential to perpetuate sleep disturbance and ultimately promote the development of insomnia. They also reported willingness to receive written information regarding this topic, which represents a relatively low-cost opportunity for intervention in the absence of dedicated CBT-I programs that remain the gold standard.

\section{Conclusions}

It is essential that the long-term goal of research on sleep disturbances in patients with cancer focuses on treatment approaches that will improve quality of life both during treatment and after completion. ${ }^{48}$ Of particular importance were our findings that the study patients reported being amenable to questioning regarding their sleep patterns, and that most thought that cancer care should incorporate dedicated sleep assessment. Based on results of this study, we are developing a patient education leaflet on sleep management for distribution in all major Irish oncology centers that will incorporate and reinforce our findings.

\footnotetext{
Submitted October 14, 2019; accepted for publication June 26, 2020.
}

Author contributions: Study concept and design: Harrold, Idris, Keegan, Collier, Kingston, O’Dwyer, Cuffe. Patient psycho-oncology support during the study: Collier, Kingston, O'Dwyer. Data collection: Harrold, Idris, Keegan, Corrigan, M. O'Donnell, Lim, Duffy, Cuffe. Data analysis and interpretation: Harrold, Idris, Keegan, Corrigan, Teo, Cuffe. Manuscript preparation: All authors. Critical review: Harrold, Idris, Keegan, Teo, D.M. O'Donnell, Kennedy, Sukor, Grant, Gallagher, Collier, Kingston, O'Dwyer, Cuffe. 
Previous presentation: This study was presented as a poster at ESMO 2016 Congress; October 7-11, 2016; Copenhagen, Denmark (Ann Oncol 2016; 27[Suppl]:Abstract 4209), and as an oral presentation at the 2016 Irish Society of Medical Oncology Meeting; January 30; Dublin, Ireland.

Disclosures: The authors have disclosed that they have not received any financial consideration from any person or organization to support the preparation, analysis, results, or discussion of this article.
Disclaimer: All procedures performed in this study were in accordance with the ethical standards of the institutional and national research committee and with the 1964 Helsinki Declaration. All participants signed informed consent prior to their inclusion in this study.

Correspondence: Emily C. Harrold, MD, Department of Medical Oncology, Mater Misericordiae University Hospital, Eccles Street, Dublin 7, Ireland. Email: emilyharrold@mater.ie

\section{References}

1. Mathers CD, Loncar D. Projections of global mortality and burden of disease from 2002 to 2030. PLoS Med 2006;3:e442.

2. Beszterczey A, Lipowski ZJ. Insomnia in cancer patients. Can Med Assoc J $1977 ; 116: 355$

3. Johns MW, Egan P, Gay TJA, et al. Sleep habits and symptoms in male medical and surgical patients. BMJ 1970;2:509-512.

4. Anderson KO, Getto CJ, Mendoza TR, et al. Fatigue and sleep disturbance in patients with cancer, patients with clinical depression, and community-dwelling adults. J Pain Symptom Manage 2003;25:307-318.

5. Given B, Given C, Azzouz F, et al. Physical functioning of elderly cancer patients prior to diagnosis and following initial treatment. Nurs Res 2001; 50:222-232

6. Mormont MC, Waterhouse J, Bleuzen P, et al. Marked 24-h rest/activity rhythms are associated with better quality of life, better response, and longer survival in patients with metastatic colorectal cancer and good performance status. Clin Cancer Res 2000;6:3038-3045.

7. Vgontzas AN, Liao D, Pejovic S, et al. Insomnia with short sleep duration and mortality: the Penn State cohort. Sleep 2010;33:1159-1164.

8. Ferrie JE, Shipley MJ, Cappuccio FP, et al. A prospective study of change in sleep duration: associations with mortality in the Whitehall II cohort. Sleep 2007;30:1659-1666.

9. Gallicchio L, Kalesan B. Sleep duration and mortality: a systematic review and meta-analysis. J Sleep Res 2009;18:148-158.

10. Heslop P, Smith GD, Metcalfe C, et al. Sleep duration and mortality: the effect of short or long sleep duration on cardiovascular and all-cause mortality in working men and women. Sleep Med 2002;3:305-314.

11. Cappuccio FP, D'Elia L, Strazzullo P, et al. Sleep duration and all-cause mortality: a systematic review and meta-analysis of prospective studies. Sleep 2010;33:585-592.

12. Condén E, Rosenblad A. Insomnia predicts long-term all-cause mortality after acute myocardial infarction: a prospective cohort study. Int J Cardiol 2016;215:217-222.

13. Choi JW, Song JS, Lee YJ, et al. Increased mortality in relation to insomnia and obstructive sleep apnea in Korean patients studied with nocturnal polysomnography. J Clin Sleep Med 2017;13:49-56.

14. Carroll JE, Seeman TE, Olmstead R, et al. Improved sleep quality in older adults with insomnia reduces biomarkers of disease risk: pilot results from a randomized controlled comparative efficacy trial. Psychoneuroendocrinology 2015;55:184-192.

15. Hu LY, Chen PM, Hu YW, et al. The risk of cancer among patients with sleep disturbance: a nationwide retrospective study in Taiwan. Ann Epidemiol 2013;23:757-761

16. Roscoe JA, Kaufman ME, Matteson-Rusby SE, et al. Cancer-related fatigue and sleep disorders. Oncologist 2007;12(Suppl 1):35-42.

17. Savard J, Morin CM. Insomnia in the context of cancer: a review of a neglected problem. J Clin Oncol 2001;19:895-908.

18. Degner LF, Sloan JA. Symptom distress in newly diagnosed ambulatory cancer patients and as a predictor of survival in lung cancer. J Pain Symptom Manage 1995;10:423-431.

19. Ginsburg ML, Quirt C, Ginsburg AD, et al. Psychiatric illness and psychosocial concerns of patients with newly diagnosed lung cancer CMAJ 1995;152:701-708.

20. Krech RL, Walsh D. Symptoms of pancreatic cancer. J Pain Symptom Manage 1991;6:360-367

21. Kurtz ME, Kurtz JC, Given CW, et al. Loss of physical functioning among patients with cancer: a longitudinal view. Cancer Pract 1993;1:275-281.

22. Malone M, Harris AL, Luscombe DK. Assessment of the impact of cancer on work, recreation, home management and sleep using a general health status measure. J R Soc Med 1994;87:386-389.

23. Couzi RJ, Helzlsouer KJ, Fetting JH. Prevalence of menopausal symptoms among women with a history of breast cancer and attitudes toward estrogen replacement therapy. J Clin Oncol 1995;13:2737-2744.
24. Engstrom CA, Strohl RA, Rose L, et al. Sleep alterations in cancer patients Cancer Nurs 1999:22:143-148.

25. Harrison LB, Zelefsky MJ, Pfister DG, et al. Detailed quality of life assessment in patients treated with primary radiotherapy for squamous cell cancer of the base of the tongue. Head Neck 1997;19: 169-175.

26. Lindley C, Vasa S, Sawyer WT, et al. Quality of life and preferences for treatment following systemic adjuvant therapy for early-stage breast cancer. J Clin Oncol 1998;16:1380-1387.

27. Sarna L, Brecht ML. Dimensions of symptom distress in women with advanced lung cancer: a factor analysis. Heart Lung 1997;26:23-30.

28. Arndt V, Koch-Gallenkamp L, Jansen L, et al. Quality of life in long-term and very long-term cancer survivors versus population controls in Germany. Acta Oncol 2017;56:190-197.

29. Gooneratne NS, Dean GE, Rogers $A E$, et al. Sleep and quality of life in long-term lung cancer survivors. Lung Cancer 2007;58:403-410.

30. Gibbins J, McCoubrie R, Kendrick $A H$, et al. Sleep-wake disturbances in patients with advanced cancer and their family carers. J Pain Symptom Manage 2009;38:860-870.

31. Delgado-Guay $M$, Yennurajalingam $\mathrm{S}$, Parsons $\mathrm{H}$, et al. Association between self-reported sleep disturbance and other symptoms in patients with advanced cancer. J Pain Symptom Manage 2011;41:819-827.

32. Derogatis LR, Feldstein M, Morrow G, et al. A survey of psychotropic drug prescriptions in an oncology population. Cancer 1979;44:1919-1929.

33. Stiefel FC, Kornblith AB, Holland JC. Changes in the prescription patterns of psychotropic drugs for cancer patients during a 10-year period. Cancer 1990;65:1048-1053.

34. Sanft T, Denlinger CS, Armenian $S$, et al. NCCN Guidelines Insights: Survivorship, Version 2.2019. J Natl Compr Canc Netw 2019;17:784-794. To view the most recent version of these guidelines, visit NCCN.org

35. Chevalier H, Los F, Boichut D, et al. Evaluation of severe insomnia in the general population: results of a European multinational survey. J Psychopharmacol 1999;13(4 Suppl 1):S21-24

36. Popovic G, Harhara T, Pope A, et al. Patient-reported functional status in outpatients with advanced cancer: correlation with physician-reported scores and survival. J Pain Symptom Manage 2018;55:1500-1508.

37. Pt-Global. PG-SGA. Accessed August 1, 2019. Available at: http://pt-global. org/?page_id=13

38. Zigmond AS, Snaith RP. The hospital anxiety and depression scale. Acta Psychiatr Scand 1983;67:361-370.

39. American Sleep Disorders Association. The International Classification of Sleep Disorders. Diagnostic and Coding Manual. Rochester, MN: American Sleep Disorders Association; 1997.

40. American Psychiatric Association. Diagnostic and Statistical Manual of Mental Disorders, 4th ed. Washington, DC: American Psychiatric Association; 1994.

41. Hamilton M. A rating scale for depression. J Neurol Neurosurg Psychiatry 1960;23:56-62.

42. Bauer J, Capra S, Ferguson M. Use of the scored Patient-Generated Subjective Global Assessment (PG-SGA) as a nutrition assessment tool in patients with cancer. Eur J Clin Nutr 2002;56:779-785.

43. Martin L, Watanabe S, Fainsinger R, et al. Prognostic factors in patients with advanced cancer: use of the patient-generated subjective global assessment in survival prediction. J Clin Oncol 2010;28:4376-4383.

44. Singer S, Kuhnt S, Götze H, et al. Hospital anxiety and depression scale cutoff scores for cancer patients in acute care. Br J Cancer 2009;100: 908-912.

45. Moorey S, Greer S, Watson M, et al. The factor structure and factor stability of the hospital anxiety and depression scale in patients with cancer. Br J Psychiatry 1991;158:255-259.

46. Annunziata MA, Muzzatti B, Altoè G. Defining Hospital Anxiety and Depression Scale (HADS) structure by confirmatory factor analysis: a 
contribution to validation for oncological settings. Ann Oncol 2011:22: 2330-2333.

47. Stepanski EJ, Wyatt JK. Use of sleep hygiene in the treatment of insomnia. Sleep Med Rev 2003;7:215-225.

48. Lis CG, Gupta D, Grutsch JF. The relationship between insomnia and patient satisfaction with quality of life in cancer. Support Care Cancer 2008;16:261-266.

49. Espie CA, Fleming L, Cassidy J, et al. Randomized controlled clinical effectiveness trial of cognitive behavior therapy compared with treatment as usual for persistent insomnia in patients with cancer. J Clin Oncol 2008; 26:4651-4658.

50. Palesh OG, Roscoe JA, Mustian KM, et al. Prevalence, demographics, and psychological associations of sleep disruption in patients with cancer: University of Rochester Cancer Center-Community Clinical Oncology Program. J Clin Oncol 2010;28:292-298.

51. Liu L, Fiorentino L, Natarajan L, et al. Pre-treatment symptom cluster in breast cancer patients is associated with worse sleep, fatigue and depression during chemotherapy. Psychooncology 2009;18: 187-194.

52. Fleming L, Randell K, Harvey CJ, et al. Does cognitive behaviour therapy for insomnia reduce clinical levels of fatigue, anxiety and depression in cancer patients? Psychooncology 2014;23:679-684

53. Kim E, Jahan $T$, Aouizerat BE, et al. Changes in symptom clusters in patients undergoing radiation therapy. Support Care Cancer 2009;17:1383-1391.

54. Fiorentino L, Rissling M, Liu L, et al. The symptom cluster of sleep, fatigue and depressive symptoms in breast cancer patients: severity of the problem and treatment options. Drug Discov Today Dis Models 2011;8: 167-173.

55. Cimprich B. Pretreatment symptom distress in women newly diagnosed with breast cancer. Cancer Nurs 1999;22:185-194.

56. Ancoli-Israel S, Liu L, Marler MR, et al. Fatigue, sleep, and circadian rhythms prior to chemotherapy for breast cancer. Support Care Cancer 2006;14:201-209.

57. Silberfarb PM, Hauri PJ, Oxman TE, et al. Assessment of sleep in patients with lung cancer and breast cancer. J Clin Oncol 1993;11:997-1004.

58. Davidson JR, MacLean AW, Brundage MD, et al. Sleep disturbance in cancer patients. Soc Sci Med 2002;54:1309-1321.
59. Berger AM, Parker KP, Young-McCaughan S, et al. Sleep/Wake disturbances in people with cancer and their caregivers: state of the science. Oncol Nurs Forum 2005;32:E98-126.

60. Savard J, Simard S, Ivers H, et al. Randomized study on the efficacy of cognitive-behavioral therapy for insomnia secondary to breast cancer, part I: sleep and psychological effects. J Clin Oncol 2005;23:6083-6096.

61. Dirksen SR, Epstein DR. Efficacy of an insomnia intervention on fatigue, mood and quality of life in breast cancer survivors. J Adv Nurs 2008;61: 664-675.

62. Berger AM, Kuhn BR, Farr LA, et al. One-year outcomes of a behavioral therapy intervention trial on sleep quality and cancer-related fatigue. $\mathrm{J}$ Clin Oncol 2009;27:6033-6040

63. Fiorentino L, McQuaid JR, Liu L, et al. Individual cognitive behavioral therapy for insomnia in breast cancer survivors: a randomized controlled crossover pilot study. Nat Sci Sleep 2010;2:1-8.

64. Jansson M, Linton SJ. Cognitive-behavioral group therapy as an early intervention for insomnia: a randomized controlled trial. J Occup Rehabil 2005:15:177-190.

65. Verbeek $I H$, Konings GM, Aldenkamp AP, et al. Cognitive behavioral treatment in clinically referred chronic insomniacs: group versus individual treatment. Behav Sleep Med 2006;4:135-151.

66. Vincent $\mathrm{N}$, Lewycky S. Logging on for better sleep: RCT of the effectiveness of online treatment for insomnia. Sleep 2009;32:807-815.

67. Bastien $\mathrm{CH}$, Morin $\mathrm{CM}$, Ouellet MC, et al. Cognitive-behavioral therapy for insomnia: comparison of individual therapy, group therapy, and telephone consultations. J Consult Clin Psychol 2004;72:653-659.

68. Mimeault V, Morin CM. Self-help treatment for insomnia: bibliotherapy with and without professional guidance. J Consult Clin Psychol 1999;67:511-519.

69. Ritterband LM, Bailey ET, Thorndike FP, et al. Initial evaluation of an Internet intervention to improve the sleep of cancer survivors with insomnia. Psychooncology 2012;21:695-705.

70. Savard J, Villa J, Simard S, et al. Feasibility of a self-help treatment for insomnia comorbid with cancer. Psychooncology 2011;20:1013-1019.

71. Savard J, Ivers $\mathrm{H}$, Savard MH, et al. Is a video-based cognitive behavioral therapy for insomnia as efficacious as a professionally administered treatment in breast cancer? Results of a randomized controlled trial. Sleep (Basel) 2014;37:1305-1314. 
Supplemental online content for:

\section{Prevalence of Insomnia in an Oncology Patient Population: An Irish Tertiary Referral Center Experience}

Emily C. Harrold, MD; Ahmad F. Idris, MD; Niamh M. Keegan, MD; Lynda Corrigan, MD; Min Yuen Teo, MD; Martin O'Donnell, MD; Sean Tee Lim, MD; Eimear Duff, MD; Dearbhaile M. O'Donnell, MD; M. John Kennedy, MD; Sue Sukor, MD; Cliona Grant, MD; David G. Gallagher, MD; Sonya Collier, DClinPsych; Tara Kingston, MD, MRCPsych, MSc; Ann Marie O'Dwyer, MD; and Sinead Cuffe, MD

J Natl Compr Canc Netw 2020;18(12):1623-1630

eTable 1: Heterogeneity of Assessment Tools

eTable 2: Frequency Distribution of Response to Patient Preference for Intervention eAppendix 1: Patient Questionnaire 


\section{eTable 1. Heterogeneity of Assessment Tools}

\begin{tabular}{|c|c|c|c|}
\hline Reference & $\mathbf{n}$ & Cancer Site/Stage & Assessment Method \\
\hline Beszterczey \& Lipowski, ${ }^{1} 1977$ & 47 & Mixed & 18-item questionnaire \\
\hline Brandberg et al, ${ }^{2} 1995$ & 144 & Melanoma/Stage II & 6-item questionnaire \\
\hline Chen et $\mathrm{al}_{,}{ }^{3} 2008$ & 115 & Lung cancer, on chemotherapy & $\begin{array}{l}\text { Pittsburgh Sleep Quality Index, EORTC } \\
\text { QLQ-C30 }\end{array}$ \\
\hline Couzi et al, ${ }^{4} 1995$ & 190 & $\begin{array}{l}\text { Postmenopausal breast/in situ or invasive } \\
\text { locoregional }\end{array}$ & 66-item questionnaire \\
\hline Davidson et al, ${ }^{5} 2002$ & 982 & Mixed/All stages & 42-item questionnaire \\
\hline Degner \& Sloan, ${ }^{6} 1995$ & 434 & Mixed/All stages & Symptom Distress Scale (13 symptoms) \\
\hline Engstrom et al, ${ }^{7} 1999$ & 150 & Breast, lung/all stages & 82-item questionnaire \\
\hline Ginsburg et al, ${ }^{8} 1995$ & 52 & Lung/All stages & Diagnostic interview schedule \\
\hline Harrison et al, ${ }^{9} 1997$ & 29 & Tongue/All stages & $\begin{array}{l}3 \text { items of the Memorial Symptoms Assessment } \\
\text { Scale }\end{array}$ \\
\hline Kaye et al, ${ }^{10} 1983$ & 30 & $\begin{array}{l}\text { Mixed/Inoperable, included patients with } \\
\text { cancer and cardiac patients }\end{array}$ & 38-item questionnaire \\
\hline Krech \& Walsh, 1991 & 39 & Pancreas/Unresectable & $\begin{array}{l}\text { Standardized institutional clinical assessment } \\
\text { tool }\end{array}$ \\
\hline Kurtz et al, ${ }^{12} 1993$ & 279 & Mixed & $\begin{array}{l}1 \text { item of McCorkle Symptom Distress } \\
\text { Scale-modified }\end{array}$ \\
\hline Lis et $a^{1},{ }^{13} 2008$ & 954 & Mixed & EORTC QLQ-C30 \\
\hline Lindley et al, ${ }^{14} 1998$ & 86 & Breast/Stage I and II & $\begin{array}{l}1 \text { item of McCorkle Symptom Distress Scale- } \\
\text { modified }\end{array}$ \\
\hline Malone et al, ${ }^{15} 1994$ & 212 & Mixed & United Kingdom Sickness Impact Profile \\
\hline Owen et al, ${ }^{16} 1999$ & 15 & Mixed & Pittsburgh Sleep Quality Index \\
\hline Palesh et al, ${ }^{17} 2010$ & 823 & Mixed/All stages & Hamilton Depression Inventory \\
\hline Portenoy et al, ${ }^{18} 1994$ & 243 & Mixed/All stages & $\begin{array}{l}3 \text { items of Memorial Symptoms Assessment } \\
\text { Scale }\end{array}$ \\
\hline Sarna ${ }^{19} 1993$ & 69 & Lung/All stages & 1 item of Symptom Distress Scale-modified \\
\hline Savard et al, ${ }^{20} 2001$ & 300 & Breast cancer & 33-item questionnaire \\
\hline Le Guen et al, ${ }^{21} 2007$ & 29 & Lung, newly diagnosed & Pittsburgh Sleep Quality Index \\
\hline Savard et al, 222011 & 962 & $\begin{array}{l}\text { Newly diagnosed nonmetastatic awaiting } \\
\text { surgery }\end{array}$ & Insomnia diagnostic interview \\
\hline
\end{tabular}

Abbreviations: EORTC QLQ-C30, EORTC Quality of Life Questionnaire Core 30.

\section{References}

1. Beszterczey A, Lipowski ZJ. Insomnia in cancer patients. Can Med Assoc J 1977;116:355.

2. Brandberg Y, Mansson-Brahme E, Ringborg U, et al. Psychological reactions in patients with malignant melanoma. Eur J Cancer 1995;31:157-162.

3. Chen ML, Yu CT, Yang CH. Sleep disturbances and quality of life in lung cancer patients undergoing chemotherapy. Lung Cancer 2008;62:391-400.

4. Couzi RJ, Helzlsouer KJ, Fetting JH. Prevalence of menopausal symptoms among women with a history of breast cancer and attitudes toward estrogen replacement therapy. J Clin Oncol 1995;13:2737-2744.

5. Davidson JR, MacLean AW, Brundage MD, et al. Sleep disturbance in cancer patients. Soc Sci Med 2002;54:1309-1321.

6. Degner LF, Sloan JA. Symptom distress in newly diagnosed ambulatory cancer patients and as a predictor of survival in lung cancer. J Pain Symptom Manage $1995 ; 10: 423-431$.

7. Engstrom CA, Strohl RA, Rose L, et al. Sleep alterations in cancer patients. Cancer Nurs 1999;22:143-148.

8. Ginsburg ML, Quirt C, Ginsburg AD, et al. Psychiatric illness and psychosocial concerns of patients with newly diagnosed lung cancer. CMAJ 1995;152:701-708.

9. Harrison LB, Zelefsky MJ, Pfister DG, et al. Detailed quality of life assessment in patients treated with primary radiotherapy for squamous cell cancer of the base of the tongue. Head Neck 1997;19:169-175.

10. Kaye J, Kaye K, Madow L. Sleep patterns in patients with cancer and patients with cardiac disease. J Psychol 1983;114:107-113.

11. Krech RL, Walsh D. Symptoms of pancreatic cancer. J Pain Symptom Manage 1991;6:360-367.

12. Kurtz ME, Kurtz JC, Given CW, et al. Loss of physical functioning among patients with cancer: a longitudinal view. Cancer Pract 1993;1:275-281.

13. Lis CG, Gupta D, Grutsch JF. The relationship between insomnia and patient satisfaction with quality of life in cancer. Support Care Cancer 2008; 16 : 261-266.

14. Lindley C, Vasa S, Sawyer WT, et al. Quality of life and preferences for treatment following systemic adjuvant therapy for early-stage breast cancer. J Clin Oncol 1998;16:1380-1387. 
15. Malone M, Harris AL, Luscombe DK. Assessment of the impact of cancer on work, recreation, home management and sleep using a general health status measure. J R Soc Med 1994;87:386-389.

16. Owen DC, Parker KP, McGuire DB. Comparison of subjective sleep quality in patients with cancer and healthy subjects. Oncol Nurs Forum 1999;26:1649-1651.

17. Palesh OG, Roscoe JA, Mustian KM, et al. Prevalence, demographics, and psychological associations of sleep disruption in patients with cancer: University of Rochester Cancer Center-Community Clinical Oncology Program. J Clin Oncol 2010;28:292-298.

18. Portenoy RK, Thaler HT, Kornblith AB, et al. Symptom prevalence, characteristics and distress in a cancer population. Qual Life Res 1994;3:183-189.

19. Sarna L. Correlates of symptom distress in women with lung cancer. Cancer Pract 1993;1:21-28.

20. Savard J, Simard S, Blanchet J, et al. Prevalence, clinical characteristics, and risk factors for insomnia in the context of breast cancer. Sleep 2001;24:583-590.

21. Le Guen Y, Gagnadoux F, Hureaux J, et al. Sleep disturbances and impaired daytime functioning in outpatients with newly diagnosed lung cancer. Lung Cancer 2007;58:139-143.

22. Savard J, Ivers H, Villa J, et al. Natural course of insomnia comorbid with cancer: an 18-month longitudinal study. J Clin Oncol 2011;29:3580-3586

\section{eTable 2. Frequency Distribution of Response to Patient Preference for Intervention}

\begin{tabular}{|c|c|c|c|c|c|c|c|c|}
\hline Score & $\begin{array}{l}\text { Sleeping } \\
\text { Tablets } \\
\text { (n) }\end{array}$ & $\begin{array}{c}\text { Written } \\
\text { Information } \\
\text { (n) }\end{array}$ & $\begin{array}{l}\text { Once-Off Sleep } \\
\text { Management } \\
\text { Lecture } \\
\text { (n) }\end{array}$ & $\begin{array}{l}\text { Series of Sleep } \\
\text { Management } \\
\text { Lectures } \\
\text { (n) }\end{array}$ & $\begin{array}{c}\text { Group Workshops } \\
\text { on Sleep } \\
\text { Management } \\
\text { (n) }\end{array}$ & $\begin{array}{c}\text { Individual Session } \\
\text { With Psychiatrist/Psychologist } \\
\text { (n) }\end{array}$ & $\begin{array}{c}\text { Cognitive } \\
\text { Behavioral } \\
\text { Therapy } \\
\text { (n) }\end{array}$ & $\begin{array}{l}\text { Mindfulness } \\
\text { Therapy } \\
\text { (n) }\end{array}$ \\
\hline $3-4$ & 32 & 23 & 19 & 29 & 36 & 26 & 34 & 33 \\
\hline $5-6$ & 34 & 31 & 37 & 36 & 38 & 44 & 35 & 32 \\
\hline
\end{tabular}




\section{eAppendix 1: Patient Questionnaire}

\section{PATIENT QUESTIONNAIRE}

Thank you for taking the time to fill out this questionnaire. It should take no more than 10-15 minutes of your time and any questions you would prefer not to answer can be omitted.

You will be asked a number of questions about yourself, your general health, and your sleeping patterns, the answers to which will all be anonymized.

The majority of questions will have a series of options and you are asked to mark the one that most applies to you. Others will have a scale and you are asked to pick the number on the scale that most applies to you.
1. Age (y): $\quad 18-24 \square \quad 25-34 \square \quad 35-44 \square \quad 45-54 \square \quad 55-64 \square \quad 65-74 \square \quad \geq 75 \square$
2. Sex:
Male
Female $\square$

3. Ethnicity:

White/Caucasian

Black/African American

Asian

Other

4. Marital status:

$\begin{array}{ll}\text { Single } & \square \quad \begin{array}{l}\text { Divorced/Separated } \\ \text { Married/Living with partner } \square\end{array} \\ \text { Widowed }\end{array}$

5. Children at home:
Yes
No
If yes, please indicate ages:

6. Highest level of education gained:

Primary school

Secondary school

University degree

College degree/technical qualification

Postgraduate Qualification (Masters/PhD)

7. Occupation: Currently working: Yes $\square$ No $\square$

8. Please check the statement that best applies to you:
Smoker
Cigar $\square \quad$ Cigarette $\square \quad$ Rolling tobacco
Ex-smoker
Please indicate quantity per day:
How long ago did you stop smoking?

Never smoker

9. Do you drink alcohol?

$$
\begin{array}{r}
\text { Yes } \square \quad \square \\
\text { If yes: More than once per week } \square \\
\text { Once per week } \square \\
\text { Once per month } \square \\
\text { Less frequently } \square
\end{array}
$$

In one week please indicate number of:

Glasses of wine:

(standard glass is $100 \mathrm{~mL}$ )

Pints of beer:

(standard pint $568 \mathrm{~mL}$ )

Glasses of spirits (pub measure of spirits is $25 \mathrm{~mL}$ ) 


\section{eAppendix 1: Patient Questionnaire (cont.)}

10. Do you drink caffeine? Yes $\square \quad$ No $\square$

If yes, please indicate amount consumed per day: (assume 1 cup $=250 \mathrm{ml}$ ) Tea: $<1$ cups $\square \quad<2$ cups $\square \quad 2-4$ cups $\square \quad>4$ cups per day

$$
\text { Coffee: }<1 \text { cups } \square \quad<2 \text { cups } \square \quad 2-4 \text { cups } \square \quad>4 \text { cups per day } \square
$$

Carbonated beverages: <1 cups $\square \quad 1-2$ drinks $\square \quad 2-4$ drinks $\square \quad>4$ drinks per day $\square$

What is the latest time in the day you would drink caffeine:

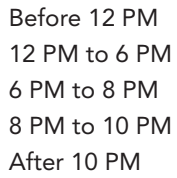

11. Which statement best describes your current level of activity:

Normal with no limitations

Not my normal self, but able to be up and about with fairly normal activities $\square$ Not feeling up to most thing, but in bed or chair less than half the day Able to do little activity and spend most of the day in bed or chair Totally confined to bed or chair

12. Which statement best describes the amount of physical activity you do in a week (eg, walking, swimming, running, working in the garden, shopping)
30 minutes at least once per week
30 minutes 1-3 times per week
30 minutes more than 3 times per week

13. From the list below please mark any of the devices you would use in the last hour before bed:

Television
Computer/Internet
iPod
Radio
Wii/PlayStation/Xbox
Other

14. Do you participate in any of the following activities (please check all that apply)

$\begin{array}{ll}\text { Yoga } & \square \\ \text { Meditation } & \square \\ \text { Pilates } & \square \\ \text { Acupuncture } & \square \\ \text { Mindfulness } & \square \\ \text { Other } & \square\end{array}$

MEDICAL HISTORY:

15. What type of cancer do you have?

Breast

Ovarian/Cervix

Uterine (womb)

Prostate

Colorectal (bowel/rectum)

Lung

Lymphoma

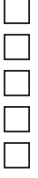

Melanoma

Head and neck

Other not listed: 


\section{eAppendix 1: Patient Questionnaire (cont.)}

16. Have you had surgery for cancer: Yes $\square$

No $\square$

Type of cancer surgery:

17. Have you been hospitalized in the last month?

$$
\begin{aligned}
& \text { Yes } \square \quad \text { No } \square \\
& \text { If yes, for how long? }
\end{aligned}
$$

18. Please indicate the statement that best applies to you regarding chemotherapy/targeted therapy:

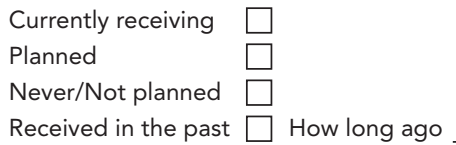

19. Please indicate the statement that best applies to you regarding Radiotherapy?

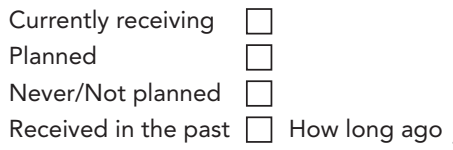

20. Do you currently attend/ or have you ever attended any of the following services? Please check all that apply to you:

$$
\begin{aligned}
& \text { Palliative care } \\
& \text { Psych-oncology } \\
& \text { Psychiatry } \\
& \text { Support group }
\end{aligned}
$$

22. Prior to your cancer diagnosis did you ever have a history of anxiety?
Yes $\square$
No $\square$
If yes, who managed your symptoms:

General practitioner

Psychiatrist $\square$

Psychologist/Counselor

Did not seek medical advice

23. Prior to your cancer diagnosis did you ever have a history of depression?
Yes
No
If yes who managed your symptoms:

General practitioner

Psychiatrist

Psychologist/Counselor

Did not seek medical advice

24. Please indicate ALL current medications:
a) Steroids, eg, dexamethasone, prednisolone:
Yes $\square$
No
No
Unsure
If yes: Do you only take around the days of chemotherapy? Ye
Do you take for reasons other than chemotherapy? Yes
No
Unsure
Unsure
What time of day do you take your last steroid: If yes:
Has anyone ever given you advice about the best time of day to take your steroids?
b) Sleeping tablets:
Yes
No $\square \quad$ Unsure $\square$
Name of tablet:
Yes $\square \quad$ No $\square \quad$ Unsure $\square$
If yes:
Every night
More than or equal to 3 nights per week $\square$
Less than 3 nights per week $\square$ 


\section{eAppendix 1: Patient Questionnaire (cont.)}

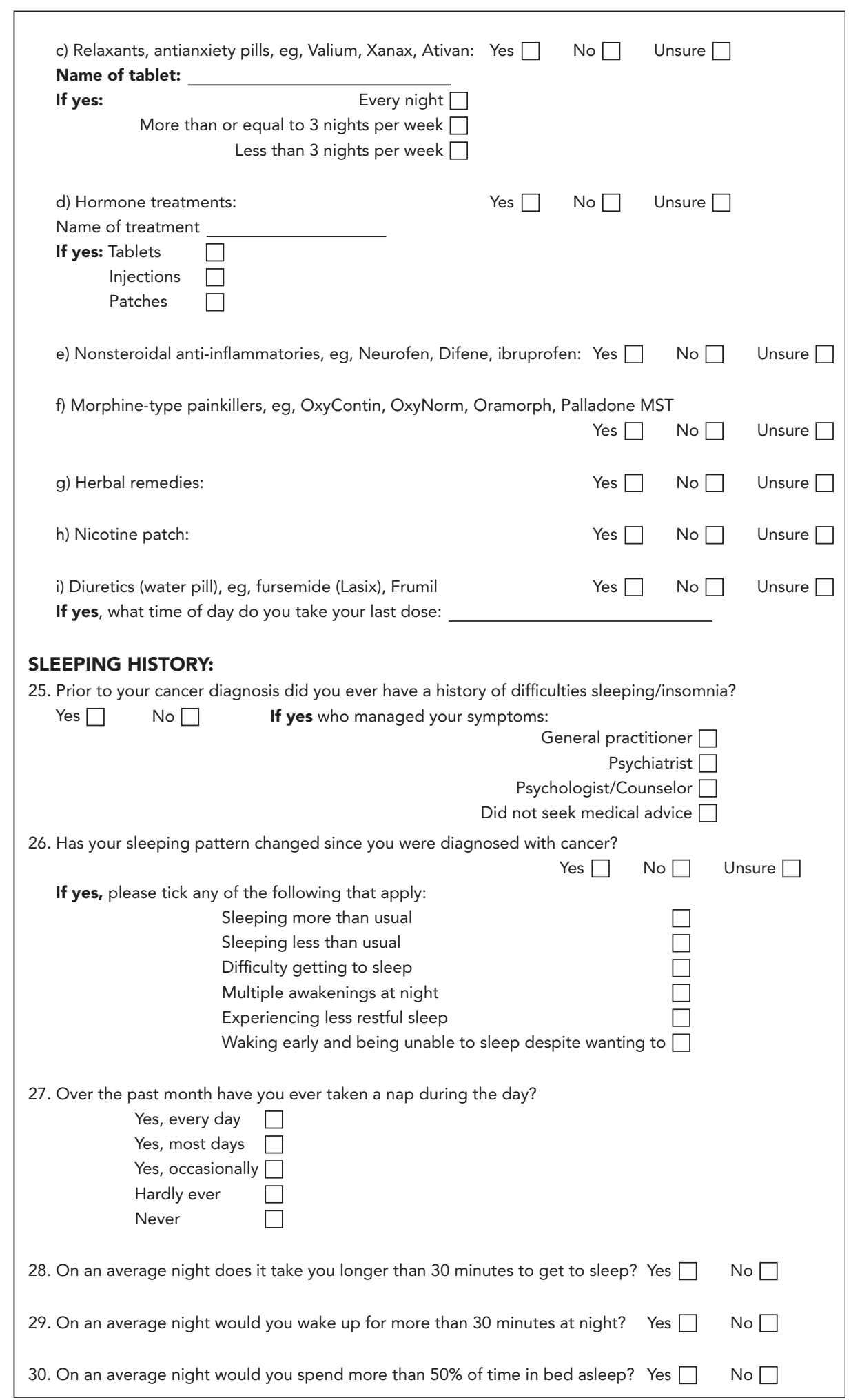

(continued) 


\section{eAppendix 1: Patient Questionnaire (cont.)}

31. Is your sleep disturbed: Less than 3 nights per week More than 3 nights per week Every night

Not disturbed

32. How long has your sleep been disturbed for: Less than 1 month More than one month but less than 6 months Greater than 6 months Sleep not disturbed $\square$

33. What interferes with your sleep:

$\begin{array}{cccc}\begin{array}{ccc}\text { Not at } \\ \text { All }\end{array} & \begin{array}{c}\text { A } \\ \text { Little }\end{array} & \begin{array}{c}\text { Quite a } \\ \text { Bit }\end{array} & \begin{array}{c}\text { Very } \\ \text { Much }\end{array} \\ 1 & 2 & 3 & 4 \\ 1 & 2 & 3 & 4 \\ 1 & 2 & 3 & 4 \\ 1 & 2 & 3 & 4 \\ 1 & 2 & 3 & 4 \\ 1 & 2 & 3 & 4 \\ 1 & 2 & 3 & 4 \\ 1 & 2 & 3 & 4 \\ 1 & 2 & 3 & 4 \\ 1 & 2 & 3 & 4 \\ 1 & 2 & 3 & 4\end{array}$

If you can think of any other factor that regularly interferes with your sleep, please specify

34. Do you think any of the following can affect your sleeping pattern?

$\begin{array}{llll}\text { Steroids: } & \text { Yes } \square & \text { No } \square & \text { Unsure } \square \\ \text { Caffeine: } & \text { Yes } \square & \text { No } \square & \text { Unsure } \square \\ \text { Alcohol: } & \text { Yes } \square & \text { No } \square & \text { Unsure } \square\end{array}$

35. Do you ever use alcohol before going to bed to help you sleep?
Yes, every day:
Yes, most days:
Yes, occasionally:
Hardly ever:
Never:

36. Indicate on a scale of 1 to 10 how much your sleep disturbance distresses you.

No distress

High level of distress

$$
\begin{array}{llllllllll}
1 & 2 & 3 & 4 & 5 & 6 & 7 & 8 & 9 & 10
\end{array}
$$

37. Do you feel your sleeping pattern influences any of the following:

Physical function during the day

$\begin{array}{lll}\text { Not at } & \text { A } & \text { Quite a } \\ \text { All } & \text { Little } & \text { Bit }\end{array}$

Very

Little Bit Much

Cognition (memory)

123

123

Mental function during day/ability to

1

perform complicated tasks

Ability to tolerate treatment

Emotions

$\begin{array}{llll}1 & 2 & 3 & 4 \\ 1 & 2 & 3 & 4\end{array}$




\section{eAppendix 1: Patient Questionnaire (cont.)}

38. As part of your medical treatment, do you think you should be asked about your sleeping patterns?

$$
\text { Yes } \square \quad \text { No } \square \quad \text { Unsure } \square
$$

39. Have you ever been asked about your sleep by a health professional?

If yes, by whom: Medical oncologist

Yes $\square \quad$ No $\square \quad$ Unsure $\square$

Radiation oncologist

Palliative care

Psychological oncology service

Nurse: Palliative care nurse

Oncology nurse

General practitioner

40. If insomnia became a problem for you, on a scale of 1 to 10 would you feel being referred for the following:

\begin{tabular}{|c|c|c|c|c|c|c|c|c|}
\hline Consideration of sleeping tablets: & 1 & 2 & 3 & 4 & 5 & 6 & $\gamma$ & \\
\hline Written advice on sleep management: & 1 & 2 & 3 & 4 & 5 & 6 & 7 & 8 \\
\hline Once time lecture on sleep management: & 1 & 2 & 3 & 4 & 5 & 6 & 7 & $\varepsilon$ \\
\hline Series of lectures on management of sleep: & 1 & 2 & 3 & 4 & 5 & 6 & 7 & \\
\hline $\begin{array}{l}\text { Group workshop led by psychologist and } \\
\text { attended by up to } 8 \text { other patients: }\end{array}$ & 1 & 2 & 3 & 4 & 5 & 6 & 7 & $\varepsilon$ \\
\hline $\begin{array}{l}\text { One-to-one sessions } \\
\text { with psychiatrist/psychologist: }\end{array}$ & 1 & 2 & 3 & 4 & 5 & 6 & 7 & $\varepsilon$ \\
\hline $\begin{array}{l}\text { Cognitive behavioural therapy(treatment } \\
\text { dealing with different thoughts and the } \\
\text { behaviors behind them): }\end{array}$ & 1 & 2 & 3 & 4 & 5 & 6 & 7 & \\
\hline Mindfulness therapy: & 1 & 2 & 3 & 4 & 5 & 6 & ' & $\varepsilon$ \\
\hline
\end{tabular}

\section{HOSPITAL ANXIETY AND DEPRESSION SCALE}

As per the original permission agreement with GL Assessment this scale cannot be reproduced in a publication or journal article resulting from the study for which permission was sought.

HADS copyright @ R.P. Snaith and A.S. Zigmond 1983, 1992, 1994

Record form items originally published in Acta Psychiatricia Scandinavica 67, 361-70, copyright@ Munksgaard

International Publishers Ltd, Copenhagen, 1983.

The edition used first published in 1994 by Nelson Publishing Company Ltd( now GL Assessment Ltd) 389 Chiswick High Road, London W4 4AL.

GL Assessment is part of the Granada Learning Group. 


\section{eAppendix 1: Patient Questionnaire (cont.)}

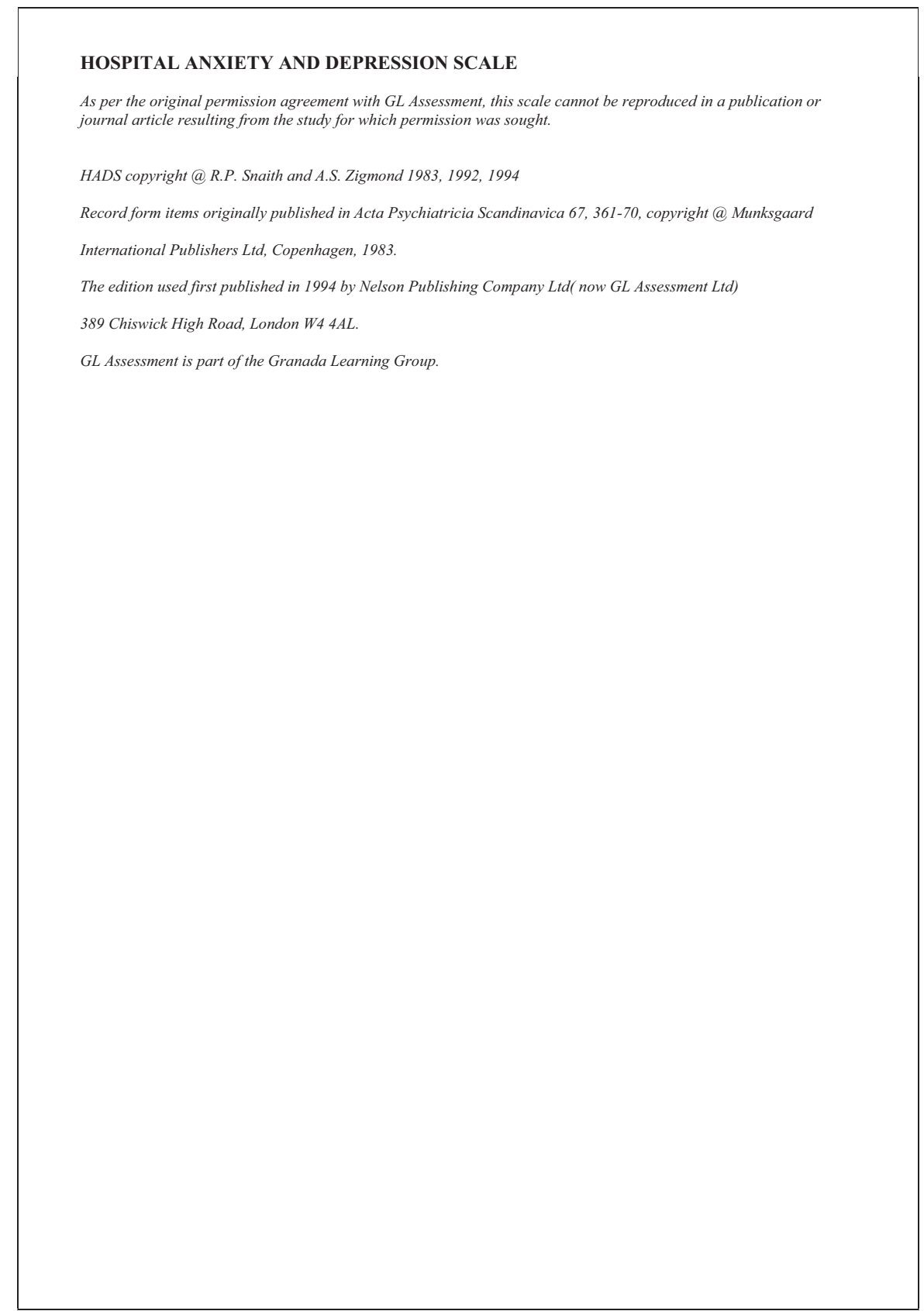

Zigmond AS, Snaith RP. The hospital anxiety and depression scale. Acta Psychiatr Scand 1983;67:361-370. 